Makale türü / Article type: Araştırma / Research

\title{
Kadın Girişimciler ve İnovasyon; Topluluktan Faydalanma Yönteminin Getirebileceği Çözümler: Şişli Bölgesindeki Kadın Girişimciler ***
}

\section{Women Entrepreneurs and Innovation; The Solutions that Crowdsourcing Can Bring: Women Entrepreneurs in Şişli District}

\author{
Zeynep Ayfer BOZAT \\ İstanbul Aydın Üniversitesi, Sosyal Bilimler Enstitüsü, Doktora Öğrencisi, \\ zeynep.bozat@kemerburgaz.edu.tr
}

\begin{abstract}
Özet
Tarih boyunca erkek arenası olarak görülen girişimciliğin kadın yüzünün gelişen ekonomilerdeki önemi şimdilerde daha iyi anlaşılmaktadır. Oysaki kadın girişimcilerin sayısı bütün dünyada gittikçe artmakta ve inovasyon başta olmak üzere ekonomiye katkıları da hızla yükselmektedir. Ancak, erkek arenasında varlık göstermeye çalışırken yaşadıkları sorunlar önlerine birer engel olarak çıkmakta ve bu sorunlara çözüm bulmakta çoğu zaman zorlanmaktadırlar. Bununla beraber, inovasyon ve topluluklardan faydalanma bu sorunlardan bazılarına çözüm getirebilecek kapasiteye sahiptir. Bu çalışmanın amacı kadın girişimcilerin sorunlarını ortaya koymak ve bu sorunlara bazı topluluklardan faydalanma yöntemleriyle çözüm önermektir. Bu anlamda, bu çalışma Şişli Bölgesi'nde rastgele seçilen 26 kadın girişimci ile yapılan görüşmeler neticesinde ortaya çıkan kadın girişimci sorunlarına yeni bir inovasyon yöntemi olan topluluklardan faydalanma ile çözümler önermektedir.
\end{abstract}

Anahtar Sözcükler: Kadın Girişimciler, İnovasyon, Topluluktan Faydalanma.

JEL Kodları: L26, M10, O30, O39

\begin{abstract}
The importance of the female face of entrepreneurship seen as the field of men throughout the history is now better understood in emerging economies. Though, the number of women entrepreneurs is growing in the whole world and their contribution to the economy notably with innovation is growing rapidly too. However, while in attempting to make their presence felt in the men's arena, the problems they face emerge as obstacles for them and mostly it is being hard for them to find solutions to these problems. In addition to that, innovation and crowdsourcing have the capacity to bring solutions to some of these problems. The aim of this study is to reveal the
\end{abstract}


problems of women entrepreneurs and to propose some solutions to these problems with crowdsourcing methods. In this sense, this study proposes solutions to the problems that have revealed at the result of the interviews of randomly selected 26 women entrepreneurs in Şişli district with crowdsourcing which is a new innovation method.

Keywords: Women Entrepreneurs, Innovation, Crowdsourcing.

JEL Codes: L26, M10, O30, O39

\section{GÍRIŞ: GİRIŞIMCILIIK VE KADIN GIRISŞIMCILER}

Girişimcilik, tarihsel olarak hep bir "erkek arenası" olarak görülmüştür (Brush, 2008). Girişimcilik, tarih boyunca farklı şekillerde tanımlanmıştır: Schumpeter (1934), "sanayinin kaptanı", Liebenstein (1968), "boşlukları algılayan ve pazarları birbirine bağlayan kahraman”, Collins ve Moore (1964), “girişimci adam”, Hebert ve Link (1982) "kilit adam” ve McClelland (1961) "firmayı (iş birimini) düzenleyen ve/veya üretkenlik kapasitesini artıran adam" olarak tanımlamışlardır (s. 205). Görüldüğü üzere, erken literatürde girişimcilik tanımlamaları üzerinde açık bir "erkek" vurgusu vardır.

Bazı yazarlar, girişimci ve girişimciliğin erkek cinsiyetli kavramlar olduğunu, yani, erkeksi çağrışımları olduğunu belirtmişlerdir (Ahl, 2006). Bunun, geleneksel olarak girişimcilerin genellikle erkek olmasından ötürü olduğu söylenebilir ancak, bazı bilim adamları kadınların medyada olduğu kadar araştırma alanında da görünmez hale getirildiğini savunmaktadırlar (Baker vd., 1997; Sundin, 1988).

Schumpeter (1934), girişimciyi, "özel bir krallık ya da genellikle, ama ille de şart değil, bir hanedan kurmak için bir rüya ve bir arzu” -ki bu ona güç ve özgürlük hissi verir- ile motive olan cesur ve kararlı bir adam olarak tanımlar. Ona göre girişimciyi, "savaşma, başkalarından üstün olduğunu kendine kanıtlama, başarının meyveleri için değil, başarının kendisi için başarma dürtüsünü” kazanma arzusu yönlendirir. Böyle adamlar nadir görülür. Birçok adam şarkı söyler, şarkı yazar, ama Caruso'lar nadirdir.

Erkeklerin girişimcilikte dünya çapında birincil derecede katılımcı olmalarından ötürü, erken literatürde erkek girişimciler vurgusunun olması hiç de şaşırtıcı değildir (Brush, 2008). Tarih bize, erkeklerin onlarca yıldır kendi 
kendine istihdam etme, iş yaratma ve iş sahibi olma konularında en aktif taraf olduğunu göstermektedir (Hebert \& Link, 1982).

Beklendiği gibi, çağdaş metinler erkek zamir kullanmaya daha az eğilimlidir. Ayrıca, merkezi tema, girişimci niteliklerinin teorize etmenin anlamlı olup olmadığının tartışılmasıdır (Ahl, 2006). Dolayısıyla, daha yeni tanımlar, girişimcilerin farklı koşullar altında değer yaratan yeni bir şeyler ortaya çıkarmak için bir dizi faaliyet yürüttüğünü ileri süren daha az cinsiyetçi tanımlardır (Acs ve Audretsch, 1993; Shane \& Venkataraman, 2000).

Amerikalı yazar ve şair Gertrude Stein'1n da söylediği gibi, “Girişimci, girişimcidir" ve boyutunun, şeklinin, renginin ya da cinsiyetinin önemi olmamalıdır. Araştırmalarda erkek ve kadın girişimcilerin kişisel demografik özellikleri benzerlik gösterirken, kadın liderliğindeki girişimlerin iş ve sanayi seçimleri, finansman stratejileri, büyüme biçimleri ve yönetim yapıları açısından farklılıkları vardır (Greene vd., 2003).

Amerika Birleşik Devletleri'nde kadınlar 1997-2002 yılları arasında milli oranın iki katı oranında yeni girişimler başlattılar ve sonuç olarak gerek iş sahibi olanların sayısı, gerek kazanılan getiri gerekse de istihdam edilen sayıs1 olsun kadınlar A.B.D. ekonomisinin itici gücü olarak kabul edilir (Center for Women's Business Research, 2002). Diğer raporlar da kadınları dünya ekonomilerinin pek çoğunda büyümenin önemli faktörleri olarak göstermektedir (Minniti, Arenius, Langowitz, 2005). Peru toplam girişimcilik faaliyetleri içinde en yüksek orana sahipken (\%39), Japonya en düşük orana $(\% 1,2)$ sahiptir. Avustralya'da, girişimciliğe kadınların katılımı yüzde 33 ile nispeten yüksektir ve kadınların toplam girişimcilik aktivite oranı artmaktadır. Danimarka'da kadınların yeni bir iş kurma oranları \%30 ve kendi kendilerini istihdam etme oranlar1 \%25'dir (Neergaard, 2006). Finlandiya'da, tüm kadınların yaklaşık yüzde 33'ü kendi kendini istihdam etmektedir (Kovalainen ve Arenius, 2006). Neredeyse tüm ülkelerde, kadın girişimcilerin dünya ekonomisinde önemli bir yeri vardır, nüfus artmakta ve kadınlar da istihdama ve gelire katkıda bulunmaktadırlar (Brush, 2008).

Türkiye'ye bakıldığında ise kadın girişimci sayısının azlığı açıkça görülmektedir. TÜİK'in en son açıkladığı 2014 Hane Halkı İşgücü Anketi sonuçlarına göre Türkiye genelinde işveren olarak çalışanlar içinde kadınların oranı $\% 8$, erkeklerin oranı ise $\% 92$ oldu (TÜİK, 2017). 
Tablo 1. Cinsiyete göre işveren olarak çalışanların dağılımı, 2014

\begin{tabular}{llll}
\hline [15+yaş] & & & \\
\hline & Toplam & Erkek & Kadın \\
\hline $\mathbf{2 0 1 4}$ & 100,0 & 92,0 & 8,0 \\
\hline
\end{tabular}

\section{GİRIŞIMCILİK VE İNOVASYON}

Zhao (2005), hızlı değişimlerin ve doğrusal olmayan dinamiklerin yaşandığ 1 bu dönemde, girişimcilik ve inovasyon birleşiminin kurumsal sürdürülebilirliğin anahtarını elinde tuttuğunu öne sürmektedir. $\mathrm{Bu}$ iki kavrama önce ayrı ayrı göz atılacak olursa, girişimcilik için Johnson'ın (2001) tanımı inovasyonla bağlantısını görmek açısından en yalın tanımlardan biri olabilir: "Girişimcilik, dar anlamda, fikirler yakalamak, onları ürün ve hizmetlere dönüştürmek ve ardından da o ürünleri pazara götürebilmek için bir girişim oluşturmayı içerir." Girişimcilik, örgütsel davranışı temsil eder. Girişimciliğin temel unsurları risk almak, proaktivite ve inovasyondur (Miller, 1983).

Ancak, Slevin and Covin (1990) bu üç unsurun örgütsel başarıyı sağlamak için yeterli olmadığını belirtmekte ve başarılı bir şirketin sadece girişimci yönetsel davranış sergilemediğini aynı zamanda bu tür davranışları desteklemek için uygun kültür ve örgütsel yapıya da sahip olduğunu öne sürmektedirler.

Bessant ve Tidd (2007) inovasyonu şöyle tanımlarlar: "Fikirlerin yararl1- ve kullanılan- yeni ürünlere, süreçlere ve hizmetlere dönüştürülmesi sürecidir". Literatürde farklı inovasyon sınıflandırmalarına rastlamak mümkündür ancak genel olarak şu şekilde bir sınıflandırma yapmak mümkün olabilir:

- Radikal ve artımsal inovasyonlar;

- Ürün veya süreç inovasyonlar1;

- Yönetsel veya teknolojik inovasyonlar (Cooper, 1998). 
İnovasyon radikal ve artımsal olabilir (Zhao, 2005). Radikal inovasyonlar, çı̆̆ır açan, aralıklı, devrimci, özgün, öncü, temel, ya da büyük inovasyonları işaret eder (Green vd., 1995). Artımsal inovasyonlar ise, var olan süreçler, ürünler ve hizmetleri uzatmak veya geliştirmek amaciyla yapılan küçük iyileştirmelerdir (Zhao, 2005). Utterback (1998), ürün ve süreç inovasyonu arasındaki ayrımı şu şekilde göstermiştir: "Ürün inovasyonu kuruluşlar tarafindan sunulan son ürün veya hizmetteki değişikliği yansitırken, süreç yeniliği ise kuruluşların ürün veya hizmeti üretme şekillerindeki değişiklikleri yansıtır”.

Daft (1978) ise, yönetsel ve teknolojik inovasyonlar arasındaki farkı şu şekilde ortaya koymuştur: "Teknolojik inovasyon, temel çıktı işlemlerini doğrudan etkileyen yeni bir fikrin kabul edilmesiyle ilgiliyken, yönetsel inovasyonlar, politikalar, kaynakların dağılımı ve örgütün sosyal yapısı ile ilgili diğer faktörleri etkileyen değişiklikleri içerir."

İlk olarak Schumpeter (1934) girişimciler ve inovasyon arasında teorik olarak bir bağlantı kurmaya çalışmıştır ve girişimcileri inovasyon yapan kimseler olarak görmüştür. Girişimcilerin inovasyon ürettiğini bu yüzden de inovasyonun ekonominin büyümesine katkıda bulunduğunu iddia etmiştir. Girişimcinin inovasyon yapan kimse olma kavramı, inovasyon sürecinde girişimcinin rolünün altı çizildiği girişimci paradigmasının temelini oluşturur. $\mathrm{Bu}$ paradigmaya göre, yeni bir fikir yalnızca temelinde yeni bir şirket kuran kimse bir girişimci olarak adlandırılabilir. Girişimcilik yaratıcı bir hareket ve bir inovasyon olarak görülmektedir. Girişimcilik, daha önce var olmayan bir şey yaratmakla ilgilidir (Zhao, 2005). Herbig ve arkadaşlarının (1994) da belirttiği gibi, "İnovasyon üç temel bileşeni gerektirir: altyap1, sermaye ve kapasite (ilk iki işi yapmak için gerekli girişimcilik kapasitesi)."

\section{CROWDSOURCING (TOPLULUKLARDAN YARARLANMA)}

Maliyetleri nedeniyle, geleneksel inovasyon şirketler için bir yük haline gelmiştir çünkü sadece içsel kaynaklar kullanılmaktadır. Bu yüzden de, şirketler inovasyon maliyetlerini azaltmak için dış kaynakları da kullanmaya niyetlenmişlerdir ve Açık İnovasyon bu noktada şirketler için yeni bir çözüm haline gelmiştir. Crowdsourcing (Topluluklardan Yararlanma) da açik inovasyonun bir aracı olarak karşımıza çıkmaktadır. Topluluklardan 
Yararlanma metodu, İnternet Teknolojileri aracılı̆̆ıyla sanal bir kalabalığın çabalarından ve fikirlerinden yararlanmayı amaçlamaktadır.

Crowdsourcing, Jeff Howe tarafindan 2006'da (Howe; 2006) ortaya atılmış bir kavramdır ve araştırmacıların ve uygulayıcıların hatırı sayılır derecede dikkatini çekmiştir. İç ve dış müşteriler tarafından çözülmesi beklenen problemlerin çözümü için kalabalıkların kullanılmasını ifade eder (Brabham; 2008).

Jeff Howe, Wired dergisinde yayınlanan makalesinde (Howe, 2006), crowdsourcing terimini "tayin edilmiş bir vekil (genellikle bir çalışan) tarafından geleneksel olarak ifa edilen bir işin alınıp tanımlanmamış, genellikle büyük bir insan topluluğuna açık çağrı biçiminde verilmesidir" şeklinde tanımlamıştır. Saxton ve arkadaşları da (Saxton vd., 2013) çalışmalarında crowdsourcing terimini şu şekilde tanımlamaktadırlar:

"Crowdsourcing örgütlerin ăgırlıkl olarak ileri internet teknolojilerini belli örgütsel görevleri yerine getirmek adına sanal bir kalabalı̆̆ın çabalarından yararlanmak için kullandıkları bir kaynaklanma modelidir.'

Crowdsourcing dağıtımı yapılmış bir problem çözme modeli olarak değerlendirilir (Brabham, 2008). Bu modelde, problem isimsiz kalabalığa açık çağrı yoluyla açılır; insanlar gelir, görevler üzerinde çalışır, çözümlerini ibraz ederler ve o platformda sunulan teşvikleri alırlar. Crowdsourcing mimarisi üç ana bileşenden oluşur: platform, başvurular ve kalabalık (Zhang \& Zhang, 2011). Platform, crowdsourcing uygulamasının yapıldığ1 aşama olacaktır, başvuru kalabalıklara yönlendirilmiş bütün görevleri içerir ve kalabalık da problemlerin çözümlerine katkı sağlayacak kişileri ifade eder.

Crowdsourcing platformu istek sahipleri ve kalabalık arasinda bir bağlantı görevi görür. İstek sahipleri ve kalabalığın tek etkileşim yolu budur. İstek sahipleri problemi platforma yükler ve kalabalığa geçirir, kalabalık problemi seçer, çözer ve istek sahiplerinin çözüme erişip, değerlendirdikleri platforma çözümü ibraz eder. Crowdsourcing istek sahibi bir görev isteği ibraz eden ve crowdsourcing sürecini başlatan bir oluşumdur. Crowdsourcing platformu bu kalabalıkların görev isteklerini başarıyla tamamlamalarını sağlayan güvenilir bir aracıdır. Crowdsourcing platformu crowdsourcing isteklerini pazarda reklamlarını yaparak, sağlayıcıların isteklere teklif vermesine izin vererek veya istek sahibinin kazanan ibrazın seçiminde 
kullanacağı kıstası belirlediği yarışma biçiminde bir dizi farklı şekilde yürütebilir. İstek sahipleri crowdsource işleminin yapılmasını istedikleri görevi platforma yüklerler ve çalışanlar yüklenmiş bu görev listesinden seçim yaparlar, seçilen görev üzerinde çalışırlar ve platforma geri ibraz ederler. İbraz edilen çözümler istek sahipleri tarafindan değerlendirilir (Thawrani vd., 2014).

Crowdsourcing (Topluluklardan Faydalanma) çok farklı şekillerde olabilir. Büyük gruplar halindeki insanlarla, küçük ekiplerle ve hatta bireylerle dahi gerçekleştirilebilir. Yakında veya gezegenin öbür ucunda yaşayan insanlardan faydalanılabilir. Crowdsourcing yoluyla, bireylerin yaratıc1 ve düşünsel güçleri ya da fiziksel güçleri kullanılabilir veya para istenebilir.

Grier (2013) ve Estellés-Arolas ve González-Ladrón-de-Guevara (2012) altı ana crowdsourcing biçimi olduğunu öne sürmektedir:

\section{Topluluk yarışmaları (Crowdcontests) veya Topluluğa} Devretmek (Crowdcasting): Sorunun veya görevin topluluğa yönlendirildiği, ilk çözümü önerene veya en iyi çözümü önerene ödül verildiği yarışma benzeri crowdsourcing türüdür (EstellésArolas ve diğerleri, 2015).

2. Büyük ölçekli görevler veya Topluluk İşbirliği (Crowdcollaboration): Süreci başlatan bir kenarda kalırken sürecin bireyler ve topluluk arasında gerçekleştiği bir crowdsourcing türüdür (Estellés-Arolas vd., 2015).

3. Küçük ölçekli görevler veya Topluluk İçeriği (Crowdcontent): Topluluk içinden daha fazla üyeyi işe dâhil edebilmek ve işin daha çabuk yapılabilmesini sağlamak için iş küçük, açık görevlere bölünmesidir.

4. Kendi kendine organize olan topluluk: Bir işin nasıl bölüneceğine topluluk karar vermesidir.

5. Topluluk fonu oluşturma (Crowdfunding): belirli bir ürünün yaratılması veya belirli bir iş fikrine yatırım yapılaması adına bireylerin nispeten küçük miktarlarda para katkısında bulunmak için interneti kullandıkları bir fonlama modelidir (Brabham, 2013). 
6. Topluluk Görüşü (Crowdopinion): Oylar, yorumlar, etiketler ve hatta hisse satışları yoluyla belirli bir sorun veya ürün hakkında kullanıcı düşüncelerini öğrenmek amaçlı kullanılan yöntemdir (Estellés-Arolas vd., 2015).

\section{4. ŞISŞLİ BÖLGESI' NDE GÖRÜŞÜLEN KADIN GİRIŞIMCİLER}

İstanbul'un Şişli ilçesinde 20 kadın girişimciyle birebir görüşme yapılmış ve genel anlamda aşağıdaki sorular yöneltilmiştir:

\begin{tabular}{l}
\hline İsletmenizi kaç yılında kurdunuz? \\
\hline $\begin{array}{l}\text { Hangi sektörde faaliyet gösteriyorsunuz? Bu sektörü seçmenizdeki ana } \\
\text { etken nedir? }\end{array}$ \\
\hline Kaç çalışanınız var? \\
\hline İşletmeniz için gelecek planlarınız nelerdir? Büyütmeyi düşünüyor \\
musunuz? Aynı sektörde mi? Neler yapmayı planlıyorsunuz? Büyütmeyi \\
düşünmüyorsanız, neden, sorun nedir? \\
İşinizin insanların hangi ihtiyacına çözüm getirmesini isteyerek bu işe \\
başladınız?
\end{tabular}

Kadın girişimci olmanın avantajları ve dezavantajları sizce nelerdir?

Kadın girişimciliği benimsetmek ve kadın girişimciliğe destek olmak için sizce neler yapılabilir?

Sivil Toplum Kuruluşları veya başka kadın girişimciler dışında ailenizde, arkadaşlarınızdan, banka veya devlet kurumlarından herhangi bir destek aldınız mı?

Yaptığınız işle ilgili diğer kişilerin yaklaşımları nasıl?

Karşılaştığınız ilk ve en büyük engel neydi veya kimdi?

İşletmenizin desteğe ihtiyaç duyduğunu düşündüğünüz en önemli konular nelerdir?

Kadın girişimcilerin 12 tanesi Lise mezunu, 6 tanesi Üniversite mezunu ve 1 tanesi de Ortaokul mezunudur. Yaşları 22 ile 55 arasında değişmektedir. İçinde bulundukları sektörler arasında tekstil, kuaförlük hizmetleri, gıda ve perakendecilik bulunmaktadır. Çalışan sayıları da 1 ile 4 arasında değişmektedir. 
İşletmelerini büyüme isteği genel olarak bulunmakta ancak maddi sıkıntı ve desteksizlik yüzünden bunu gerçekleştirmemekteler. Büyük çoğunluğu aile dışında herhangi bir kurumdan destek almadan girişim yaptıklarını belirtmişlerdir. Ailelerinin ve arkadaşlarının desteklerinin itici güç olduğunu bildirmişlerdir. Erkek egemen bir ticaret hayatında daha katı olmak zorunda kaldıklarını ancak Kadın olmanın da bulundukları sektöre katkıları olduğunu dile getirmişlerdir.

En çok zorlandıkları konular genel olarak şu şekildedir:

1. Maddi sıkıntı, maddi destek alamamak,

2. Kira,

3. Mal alımı,

4. Eleman bulma zorluğu.

Crowdsourcing yöntemi içerisinde kadınların sorunlarına çözüm bulabilecekleri üç yol olduğu söylenebilir:

\section{Topluluk yarışmaları (Crowdcontests) veya Topluluğa Devretmek} (Crowdcasting): Kadın girişimci kendi içinde çözüm bulamadığı büyük sorunları veya işleri bir topluluğa devredebilir ve eleman parası ödemeden topluluktan gelecek yanttlarla ve çözümlerle sonuca gidebilir. Sözgelimi, kendi iş için tasarlaması gereken bir web sayfası, logo, vs. gibi işler hem para hem de ekstra eleman gerektiren işler olabilir. Ekstra eleman almadan, büyük paralar ödemeden bir yarışma yoluyla işe çözüm getirilebilir. Aynı zamanda bu şekilde daha büyük bir kitleye ulaşma şansı da olacaktır.

2. Topluluk fonu oluşturma (Crowdfunding): $\mathrm{Bu}$ yöntem maddi destek isteyen Kadın Girişimciler açısından en çok kullanılabilecek yöntemdir. Internet üzerinden işi için başlatacağ gelecek küçük bağışlarla büyük bir fon oluşturabilir. Sektöre yeni adım atan şarkıcı adaylarının Internet üzerinden bu yöntemi sıklıkla kullandığını görebiliyoruz.

3. Topluluk Görüşü (Crowdopinion): Kadın Girişimciler bu yöntemi de bir pazarlama yöntemi olarak kullanabilirler. Bu yolla belli bir kitlenin bir ürün, mağaza yeri, paket vs. gibi şeyler üzerine fikri alınabilir ve ihtiyaç giderilecek şekilde israfa yol açmadan yapılacak 
şeyler belirlenebilir. Sosyal medya üzerinden hem girişimin hem de ürünün tanıtımı yapılabilir, topluluğun fikri alınabilir.

\section{SONUÇ VE ÖNERILER}

Erkek egemen bir dünya olan girişimcilik dünyasında Crowdsourcing (Topluluklardan Yararlanma) yöntemi Kadın girişimcilere çözüm önerileri sunabilir. Yukarıda saydığımız yöntemler, Kadın girişimcilerin internet üzerinden daha geniş bir kitleye açılmalarına, eleman açısından daha büyük bir yetenek havuzuna ulaşmalarına ve hatta girişimlerini başlatabilmek için gerekli maddi desteği bulmalarına bile yardımcı olabilecek yöntemlerdir. Çok yeni bir kavram olan Topluluklardan Yararlanma, topluluğun gücünü ortaya koyabilmek için ortaya atılmış bir kavramdır. Gittikçe daha çok benimsenen ve kullanılan bu yöntemin ilerleyen zamanlarda daha çok karşımıza çıkacağ 1 ve çeşitleneceği muhakkaktır. Dolayısıyla, bu kavramın geleceğini ve gelişimini takip etmekte fayda vardır.

\section{KAYNAKLAR}

Acs, Z., \& Audretsch D. B. (1993). Innovation and Technological Change: The new Learning, in G. D. Libecap (ed.) Advances in the Study of Entrepreneurship, Innovation and Economic Growth. Greenwich. CT: JAI Press. 109-42.

Ahl, H. (2006). Why Research on Women Entrepreneurs Needs New Directions. Entrepreneurship Theory and Practice. September, 595-621.

Baker, T., Aldrich, H.E., \& Liou, N. (1997). Invisible entrepreneurs: The neglect of women business owners by mass media and scholarly journals in the USA. Entrepreneurship and Regional Development, 9(3), 221-238.

Bessant, J., \& Tidd, J. (2007). Innovation and Entrepreneurship. Chichester: John Wiley.

Brabham, D. C. (2008, June). Moving the Crowd at iStockphoto: The composition of the Crowd and Motivations for Participation in a Crowdsourcing Application. First Monday, Vol. 13, no. 6, 1-22.

Brabham, D. C. (2008). Crowdsourcing as a model for problem solving: An introduction and cases. Convergence, February, Vol. 14, no. 1, 75-90.

Barabham, D.C. (2013). Crowdsourcing. MIT Press. London, UK.

Brush, C.G. (2008). Women Entrepreneurs: A Research Overview. The Oxford Handbook of Entrepreneurship. Edited by Anuradha Basu, Mark Casson, Nigel Wadeson, and Bernard Yeung. Oxford University Press.

Center for Women's Business Research (2002). New Analysis Documents Employment and Revenue Distribution of Women-Owned Firms in 2002 (August 27). www.womensbusinessresearch.org 
Collins, O. F. \& Moore, D. G. (1964). The Enterprising Man. East Lansing: Bureau of Business and Economic Research, Graduate School of Business Administration, Michigan State University.

Cooper, R.J. (1998). A Multidimensional Approach to The Adoption Of Innovation. Management Decision, Vol. 36, No. 8, 493-502.

Estellés-Arolas, E. \& González-Ladrón-de-Guevara, F. (2012a). Towards An İntegrated Crowdsourcing Definition. Journal of Information science, 38(2), 189-200.

Green, S., Gavin, M. \& Aiman-Smith, L. (1995). Assessing a Multidimensional Measure of Radical Technological Innovation. IEEE Transactions on Engineering Management, Vol. 42, No. 3, 203-14.

Greene, P.P., Hart, M.M., Gatewood, E.J., Brush, C. G., \& Carter, N.M. (2003). Women Entrepreneurs: Moving Front and Center: An Overview of Research and Theory. Coleman White Paper Series, http://www.unm.edu/ asalazar/Kauffman/Entrep_research/e_women.pdf (Erişim Tarihi: 29.01.2017).

Hebert, R. F. \& Link, A. N. (1982). The Entrepreneur: Mainstream Views and Radical Critiques. New York: Praeger Publishing.

Herbig, P., Golden, E.J. \& Dunphy, A. (1994), The Relationship of Structure to Entrepreneurial and Innovative Success. Marketing Intelligence \& Planning, Vol. 12 No. 9, pp. 37-48.

Howe, R. (2006) The Rise of Crowdsourcing. Wired, Vol. 14, no. 6, pp.1-4, June.

Kolvalainen, A. \& Arenius, P. (2006). Country Report on Finland, in C. Brush, N. Carter, E. Gatewood et al. (eds) The Diana Project International: Growth Oriented Women Entrepreneurs and their Businesses: A Global Research Perspective (New Horizons in Entrepreneurship). London: Elgar.

Liebenstein, H. (1968). Entrepreneurship and Development. American Economic Review. (May) 58.

Mc Clelland, D. (1961). The Achieving Society. New York: The Free Press.

Miller, D. (1983). The Correlates of Entrepreneurship in Three Types Of Firms, Management Science, Vol. 29 No. 7, 770-91.

Minniti, M., Arenius, P. \& Langowitz, N. (2005). Global Entrepreneurship Monitor: 2004 Report on Women and Entrepreneurship. Babson Park, MA London: Babson College London Business School.

Neergaard, H. (2006). Country Report on Denmark, in C. Brush, N. Carter, E. Gatewood et al. (eds) The Diana Project International: Growth Oriented Women Entrepreneurs and their Businesses: A Global Research Perspective (New Horizons in Entrepreneurship). London: Elgar.

Saxton, G. D., Onook O. \& Rajiv K.(2013). Rules of Crowdsourcing: Models, Issues, and Systems of Control. Information Systems Management, 30, 2-20.

Schumpeter, J. (1934). The Theory of Economic Development. Cambridge, MA: Harvard University Press.

Shane, S. \& Venkataraman, S. (2000). The Promise of Entrepreneurship as a Field of Research. Academy of Management Review, 25: 217-26. 
Slevin, D.P. \& Covin, J.G. (1990). Juggling Entrepreneurial Style and Organizational Structure: How to Get Your Act Together. Sloan Management Review, Vol. 31 No. 2, 43-53.

Sundin, E. (1988). Invisualizing Women- The Example of Business Enterpriser. Kvinnovetenskaplig tidsskrift, 9(1), 3-15.

Thawrani, V., Londhe, N. D., \& Singh, R. (2014, May-Jun). Crowdsourcing of Medical Data. Iete Technical Review, Vol 31, No 3.

Utterback, J.M. (1994). Mastering the Dynamics of Innovation. Harvard Business School Press, Boston, MA.

Zhang, L \& Zhang H. (2011). Research of Crowdsourcing Model Based on Case Study. 8th International Conference on Service Systems and Service Management (ICSSSM). IEEE, Tianjin, 1-5. June 25-27.

Zhao, F. (2005). Exploring The Synergy Between Entrepreneurship And Innovation. International Journal of Entrepreneurial Behaviour \& Research, Vol. 11, No. $1,25-41$.

TÜİK (2017) http://www.tuik.gov.tr/PreHaberBultenleri.do?id=21529 (Erişim Tarihi: 27.01.2017). 